\title{
Prevalence of Staphylococcus aureus and Antimicrobial Susceptibility Test in Milk and Cheese from Hadman Farm Dairies
}

\author{
Ludmilla Santana Soares e Barros ${ }^{1 *}$, Jana Kelly dos Santos ${ }^{2}$ and \\ Adriana dos Santos Silva ${ }^{1}$ \\ ${ }^{1}$ Universidade Federal do Recôncavo da Bahia (UFRB). Rua Rui Barbosa 710, Center, Cruz \\ das Almas BA Brazil, 44.380-000 \\ ${ }^{2}$ Instituto Federal de Alagoas (IFAL). Rual7 de Agosto s/n, Centro, Satuba AL \\ Brazil, 57120-000 \\ *Corresponding author
}

\section{A B S T R A C T}

A study was undertaken in Alagoas, Brazil, to determine the prevalence, associated risk factors and antimicrobial susceptibility of Staphylococcus aureus in milk and cheese from artisan handman dairies. Alleged S. aureus isolates $(\mathrm{n}=70)$ were identified out of 100

Keywords

Staphylococcus aureus,

Antimicrobial

Susceptibility, Hadman

Farm Dairies

Article Info

Accepted:

04 May 2018

Available Online:

10 June 2018 samples. Most isolates (66\%) derived from raw milk and 34\% came from cheese. Two hundred (50\%) subclinical and $20(40 \%)$ clinical cases out of 250 cross-breed lactating dairy cows examined for mastitis with CMT screening test and clinical examination, were found positive. Current study shows that the prevalence of Staphylococcus aureus was significantly associated with mastitis $(\mathrm{p}<0.05)$ and revealed that $S$. aureus has $0 \%$ susceptibility to penicillin $\mathrm{G}$, followed by tetracycline $(15 \%)$. However, these randomly selected isolates were found to be totally (100\%) susceptible to kanamycin. There should be a regular antimicrobial sensitivity testing, not only in the area under analysis, but also at a national level to select effective antibiotics against $S$. aureus mastitis. Proper prevention and regular antimicrobial sensitivity testing help select effective antibiotics and ultimately reduce the development of resistance towards commonly used antibiotics. Results demonstrate that mastitis caused by $S$. aureus is one of the major issues in milk production and imposes public health hazard in the area under analysis. Every possible control and prevention strategies should be implemented.

\section{Introduction}

Around the world, the quality of milk for human consumption has been worrying researchers and authorities, due to its nutritional, economic-social and public health importance, since the use of microbiological quality can lead to and risks to consumer health. However, most dairy farms in Brazil and in developing countries technology, deficiency in animal health control and hygiene, generating a known product of low quality. Milk is naturally a nutrient-rich culture medium, which makes it susceptible to attack by a large number of microorganisms in the environment, of the animal itself, of the 
man and of the utensils used (Barros et al., 2011a,b; Hennekinne and Loir, 2014; RajicSavic et al., 2015; Sandes et al., 2016; Santos et al., 2016; Mehli et al., 2017). In fact, in Brazil, the microbiological quality of raw milk produced in several regions of the country is poor, with high concentrations of microorganisms that indicate hygienicsanitary conditions such as mesophiles and thermotolerant coliforms and Staphylococcus aureus. Food of animal origin, especially milk and milk products, associated with outbreaks of food poisoning, public health problem and $S$. aureus, since it is the main etiological agent of bovine mastitis, turns raw milk into a large vehicle of these outbreaks (Peles et al., 2007; Barros et al., 2011a,b; Hennekinne and Loir, 2014; Rajic-Savic et al., 2015; Sandes et al., 2016; Santos et al., 2016).

In staphylococcal food poisoning, symptoms occur between 2 and 4 hours after the ingestion of the preformed toxin in the food and the most common are vomiting, nausea, abdominal pain and diarrhe. The minimum amount of enterotoxin necessary to cause the disease is not known, but the ingestion of, at least less, $1 \mu \mathrm{g}$ of toxin in $100 \mathrm{~g}$ of food already induces the appearance of clinical symptoms and this level of toxin is reached when the population of $S$. aureus exceeds $10^{5}$ per gram and the dose minimum of enterotoxins ingested for the occurrence of these symptoms is lower, of $10 \mathrm{ng}$ (Peles et al., 2007; Even et al., 2010; Barros et al., 2011a,b; Hennekinne and Loir, 2014; Sandes et al., 2016; Santos et al., 2016; Mehli et al., 2017).

Several studies have been undertaken on the quality of bovine bulk milk and on the prevalence of pathogens in cheese, especially in raw milk cheese. Current study presents a holistic approach by sampling CPS and $S$. aureus at different stages in the cheesemanufacturing process and by assessing results and consequences through (i) the quantification of CPS contamination, (ii) its associated risk factors in the study area and (iii) the assessment of the possible proportion of antibiotic resistance in the $S$. aureus population. The possible risk of $S$. aureus from products derived from artisan cheese farm dairies is discussed.

\section{Materials and Methods}

\section{Sampling and California Mastitis Test (CMT)}

Current study was performed in the state of Alagoas, northeastern Brazil. Samples were obtained from dairies in the towns of Maceió, Coruripe, Capela, Chã Preta and Quebrangulo, between October 2016 and May 2017. Ten farm dairies producing cheese from bovine milk in the region of Alagoas participated in the project. The farm dairies were asked to provide the following samples: raw milk and cheese milk (pasteurized, if applicable), and further information on the farm, the dairy and production, by filling a questionnaire. Supplementary information was collected through the respective county administrations. The producers were supplied with all the necessary equipments and instructions for sampling. The milk and cheese milk samples were packed in insulated polystyrene boxes with refrigerant gel packs and returned within two days. The box temperature was registered on arrival. Temperature of samples varied between $0^{\circ} \mathrm{C}$ and $4^{\circ} \mathrm{C}$, average $1.6^{\circ} \mathrm{C}$ and stored at $4^{\circ} \mathrm{C}$ until analysis the following day. Samples were transported in thermal boxes to the Laboratory of Food Inspection of the Universidade Federal Rural de Pernambuco and analyzed within $24 \mathrm{~h}$.

Each selected lactating cow was screened for mastitis by clinical examinations and California Mastitis Test. Clinical examination of the udder was based on a previously 
indicated method. Clinical findings include abnormalities of secretion, abnormalities of udder and teat, and systemic reaction. CMT was performed according to previously established method (Seyouma et al., 2018): approximately $2 \mathrm{ml}$ of milk from each quarter of the udder were placed in each of four shallow cups in the CMT paddle and an equal amount of the reagent was added. A gentle circular motion was applied, at a horizontal plane, for $15 \mathrm{~s}$. Result was based on gel formation, or rather, negative, if no gel was formed, and positive, if there was gel formation in at least one quarter. Gel formation ranged between Trace $(\mathrm{T})$ and +3 . Hence, a cow was considered positive for mastitis if one or more quarters were CMT positive, regardless of the microorganisms' isolation.

Quantification of CPS in milk; isolation and identification of $S$. aureus (Mehli et al., 2017)

Milk samples were mixed gently by inverting the sample tubes; ten-fold dilutions of the milk were made with sterile peptone water $(1.0 \mathrm{~g}$ bacteriological peptone and $8.5 \mathrm{~g} \mathrm{~L}^{-1}$ sodium chloride). Cheese samples were prepared by homogenizing $25 \mathrm{~g}$ of cheese and $225 \mathrm{~mL}$ of sterile peptone water for $1 \mathrm{~min}$ in Stomacher bags (Stomacher® 400 Classic Standard Bag, Seward Limited, Worthing UK). Additional ten-fold dilutions were prepared with sterile peptone water. The appropriate dilutions were spread on Bairde Parker Agar (BP) (CM0275, Oxoid, Basingstoke, UK) and egg yolk tellurite emulsion (SR0047C, Oxoid) was added for the quantification of CPS, following NMKL method 66. The plates were incubated at $37^{\circ} \mathrm{C}$ for $48 \mathrm{~h}$. Up to five typical colonies from each sample were isolated: black or grey, shining and convex with diameter $1.0-1.5$ $\mathrm{mm}$ after $24 \mathrm{~h}$, and often surrounded by a clear zone. They were further propagated to pure cultures on Brain Heart Infusion Agar (BHIA)
(CM1136, Oxoid) and preserved in Brain Heart Infusion (BHI) (CM1135, Oxoid) containing $20 \%$ glycerol bi-distilled $99.5 \%$ (VWR chemicals, Leuven, Belgium) at $80^{\circ} \mathrm{C}$. All isolates were gram-stained with Gram's Iodine (PL7003, Pro-lab Diagnostics, Bromborough, Wirral, UK) and tested for catalase activity and coagulase production. Further, coagulase positive staphylococcal isolates were streaked on p-agar, supplemented with $7 \mathrm{mg} \mathrm{L}^{-1}$ acriflavine (A8251, Sigma \& Aldrich, St. Louis, MO, USA). Positive reaction indicated growth at full length of the streak. Isolates with positive reactions described above were considered to be $S$. aureus.

\section{Testing for antimicrobial susceptibility}

Antibiotic susceptibility tests were carried out on selected $S$. aureus isolates and their susceptibility profile was determined with Kirby-Baur disc diffusion method on MuellerHinton Agar, following procedures described by (Aqib et al., 2017). Selected isolates from nutrient agar were first cultured in nutrient broth overnight. A suspension of each test isolate was compared to a turbidity equivalent to 0.5 McFarland standard, while each suspension was streaked onto Mueller Hinton Agar (Oxoid, UK) by sterile swab. Oxoid antimicrobial susceptibility disks (Oxoid, Basing Stoke, UK) with their corresponding concentration, Erythromycin (15 $\mu \mathrm{g})$, Vancomycin $(30 \mu \mathrm{g})$, Chloramphenicol (30 $\mu \mathrm{g})$, Tetracycline $(30 \mu \mathrm{g})$, Kanamycin $(30 \mu \mathrm{g})$, Sulphamethoxazole $(25 \mu \mathrm{g})$ and Penicillin (10 units) were positioned on the plates, with a sterile forceps. Inoculated plates were incubated at $37^{\circ} \mathrm{C}$ for $24 \mathrm{hr}$. The inhibition zone was then recorded as the diameter of the zone surrounding the individual disc in which bacterial growth was absent. Isolates were thus defined as resistant, intermediate and susceptible, according to the guide lines of XXXXX. 


\section{Statistical analysis}

One-way analysis of variance (ANOVA) was performed to compare the mean levels of CPS in different groups of milk samples, followed by Tukey's HSD (honest significant difference) test, on log-transformed data with statistical software SPSS Statistics 22 (IBM Corp., Chicago, IL, USA). A significance level of $p \leq 0.05$ was used, and a bacterial count equal to zero was scored as $1 \mathrm{cfu} \mathrm{g}^{-1}$ or $\mathrm{mL}^{-1}$.

\section{Results and Discussion}

\section{The farm dairies and prevalence of mastitis}

Five of the ten invited farm dairies participated in the study. These farms were in the state of Alagoas, northeastern Brazil. Samples were obtained from dairies in the towns of Maceió, Coruripe, Capela, Chã Preta and Quebrangulo, a region of untouched nature, interspersed with small villages and a couple of cities.

Farms A and E (Table 1) are located less than $15 \mathrm{~km}$ from each other, whereas Farms B and $\mathrm{D}$ are distant more than $30 \mathrm{~km}$ from each other. Farm $\mathrm{C}$ is more than $40 \mathrm{~km}$ from the others. Participating farms provided the same treatment to milk before cheese manufacturing and types of cheese produced. All cheese milk from the farm dairies was pasteurized (Table $1)$.

Two hundred (50\%) subclinical and 20 (40\%) clinical cases out of 250 cross-breed lactating dairy cows examined for mastitis by CMT screening test and clinical examination, were positive (Table 2).

\section{CPS in milk and cheese}

S. aureus isolates $(\mathrm{n}=70)$ were identified from 100 samples. Most isolates derived from raw milk (66\%), while $34 \%$ were from cheese. Mean CPS level in raw milk from different farm dairies varied between $4.5 \log \mathrm{cfu} \mathrm{mL}^{-1}$ and $6.2 \mathrm{log} \mathrm{cfu} \mathrm{mL}^{-1}$ (Table 2). CPS occurred in $22 \%$ (A), $82 \%$ (B), 37\% (C), 50\% (D) and $53 \%$ (E) of samples. The prevalence of CPS in cheese milk samples from non-pasteurized cheese production was $100 \%$, with mean 1.5 $\log$ cfu mL $\mathrm{mL}^{-1}$ and $3.3 \mathrm{log}$ cfu mg ${ }^{-1}$ (Table 3). Mean CPS level in cheese made from nonpasteurized milk was not significantly lower than that in raw milk. All isolates were susceptible to the antibiotics included in this study, except penicillin G. Further, S. aureus were found to be highly susceptible and resistant to kanamycin $(100 \%)$ and penicillin $\mathrm{G}(100 \%)$, respectively, as Table 4 shows.

Current analysis revealed (Table 1 and 2) that all raw milk samples contained CPS, with the levels ranging between 4.5 and $6.2 \log \mathrm{cfu}$ $\mathrm{mL}^{-1}$, corroborating most studies on CPS in raw milk conducted during the last decade (D'Amico and Donnelly, 2010; Barros et al., 2011a,b; Jakobsen et al., 2011; Walcher et al., 2014; Sandes et al., 2016; Santos et al., 2016; Mehli et al., 2017), with a prevalence ranging between $47.2 \%$ and $94.3 \%$.

In corroboration to observations by others researchers (Rosengren et al., 2010; Barros et al., 2011a,b; Sandes et al., 2016; Santos et al., 2016; Mehli et al., 2017) the quality of milk common to human consumption has always been a search of researchers and competent authorities for their nutritional importance, social health and public health, since milk with poor microbiological quality can lead to economic losses and risks to consumer health. In Brazil, a larger dairy farm, low technology, lack of control hygiene, generating a product of low quality. Its rich in nutrients, the size is susceptible to attack by a large number of micro-organisms of the environment, of the animal itself, of man and utensils and equipment used in milking. 
Table.1 Information on production retrieved from the questionnaire answered by the participating farm dairies

\begin{tabular}{|c|c|c|c|c|c|}
\hline Farm dairy & A & B & C & $\mathbf{D}$ & $\mathbf{E}$ \\
\hline Pasteurized product & No & No & No & No & No \\
\hline Type of cheese & Soft & Soft & Soft & Soft & Soft \\
\hline Cheese production $\left(\mathrm{kg}\right.$ year $\left.^{-1}\right)$ & 200 & 250 & 250 & 330 & 240 \\
\hline $\begin{array}{c}\text { Supplementary milk from other } \\
\text { farms }\end{array}$ & Yes & Yes & Yes & Yes & No \\
\hline $\begin{array}{l}\text { Exchange of ingredients with other } \\
\text { producers }\end{array}$ & Yes & Yes & Yes & Yes & No \\
\hline Water service provision & No & No & No & No & No \\
\hline Frequency of mastites & Constantly & Constantly & Constantly & Constantly & Constantly \\
\hline
\end{tabular}

${ }^{\mathrm{a}}$ Constantly, $\geq 2$ per annum.

Table.2 Prevalence of Staphylococcus aureus in sub-clinical and clinical mastitis cases

\begin{tabular}{|c|c|c|c|}
\hline Type of mastitis & Number of examined animals & Number of isolated S. aureus & Prevalence \\
\hline Subclinical & 200 & 100 & $\mathbf{5 0 \%}$ \\
\hline Clinical & 50 & $\mathbf{1 2 0}$ & $\mathbf{4 0 \%}$ \\
\hline TOTAL & $\mathbf{2 5 0}$ & $\mathbf{4 8 \%}$ & \\
\hline
\end{tabular}


Table.3 Coagulase positive staphylococci (CPS) in milk, whey and cheese samples from five different farm dairies ${ }^{\text {a }}$

\begin{tabular}{|c|c|c|c|c|}
\hline \multirow[t]{2}{*}{ Milk treatment } & \multirow[t]{2}{*}{ Type of cheese } & \multirow[t]{2}{*}{ Farm dairy } & \multicolumn{2}{|c|}{ Coagulase positive staphylococci (log cfu mL $\left.\mathrm{m}^{-1}\right)$} \\
\hline & & & Raw milk & Cheese Milk \\
\hline \multirow{5}{*}{ Non-pasteurized } & Soft & A & 4.5 & 1.5 \\
\hline & Soft & B & 6.2 & 3.3 \\
\hline & Soft & $\mathrm{C}$ & 4.8 & 4.0 \\
\hline & Soft & $\mathrm{D}$ & 5.5 & 3.0 \\
\hline & Soft & $\mathbf{E}$ & 5.3 & 2.5 \\
\hline
\end{tabular}

${ }^{a}$ Data are mean standard deviation $(\mathrm{n}=3$, in each group). Estimates of CPS per $\mathrm{mL}$ milk or per $\mathrm{g}$ cheese are pre-formed using log-transformed data, and counts equal to zero were scored as $1 \mathrm{CFU} \mathrm{mL} \mathrm{L}^{-1}$ or $\mathrm{g}^{-1}$.

Table.4 Summary of antimicrobial susceptibility test

\begin{tabular}{|c|c|c|c|}
\hline Antimicrobials used plus concentration & \multicolumn{3}{|c|}{ Susceptibility } \\
\hline & Susceptible $\%$ & Intermediate \% & Resistant \% \\
\hline Erythromycin $\mathbf{1 5} \boldsymbol{\mu g}$ & 90 & 10 & $\mathbf{0}$ \\
\hline Vancomycin $\mathbf{3 0} \boldsymbol{\mu g}$ & $92.9 \%$ & 9 & $\mathbf{0}$ \\
\hline Chloramphenicol $\mathbf{3 0} \boldsymbol{\mu g}$ & 91 & 0 & $\mathbf{0}$ \\
\hline Tetracycline $\mathbf{3 0} \boldsymbol{\mu g}$ & 15 & $\mathbf{5 0}$ & $\mathbf{0}$ \\
\hline Kanamycin $\mathbf{3 0} \boldsymbol{\mu g}$ & 100 & 15 & $\mathbf{0}$ \\
\hline Sulphamethoxazole $\mathbf{2 5} \boldsymbol{\mu g}$ & 85 & $\mathbf{0}$ & $\mathbf{1 0 0}$ \\
\hline Penicillin G $\mathbf{1 0}$ units & $\mathbf{0}$ & & \\
\hline
\end{tabular}


It should be underscored that, at an initial concentration of $3.0 \mathrm{log} \mathrm{cfu} \mathrm{mL}^{-1}$, as reported in current study (Table 1 and 2) and according to Duquenne et al., (2016), growth of $S$. aureus may reach above $5 \log \mathrm{cfu} \mathrm{mL}^{-1}$ during the first $6 \mathrm{~h}$ of milk renneting. The levels of $S$. aureus during cheese-making on Farm B may reach levels associated with enterotoxin production, with optimal growth conditions. In fact, generation time for $S$. aureus in milk is reported to be $0.8 \mathrm{~h}$ at $25^{\circ} \mathrm{C}$ (Le Marc et al., 2009).

Current study reveals the prevalence of Staphylococcus aureus significantly associated with mastitis $(\mathrm{p}<0.05)$. The high frequency of $S$. aureus in cases of mastitis can be explained by the fact that the humerus skin is one of the main localization factors of these agents, which facilitates the infection by this microorganism (Rahman et al., 2009; Michelle, 2011; Fitsum, 2016; Seyouma et $a l ., 2018)$. In addition to this, the higher the parity, or the higher number of times the cow has calved, is associated with lower chance of cure rates, this is due to a much larger mammary gland developed and therefore a much larger volume of tissue or an antibiotic is unable to penetrate and clear of infection (Michelle, 2011).

The literature points out that poor management practices increase susceptibility to mastitis by Staphylococcus aureus. In fact, it can be identified by post-partum somatic cell count (CCS), indicating that the animal was exposed to poor environmental condition, or there was inefficiency in the treatment of infections in the dry period. The way the animal is milked is a factor that can significantly predispose to mastitis, if this occurs manually, the milker should have many hygienic care, such as hand washing, cleaning the ceilings, among others; and if milking is performed mechanically the equipment must be strictly septic. Other aspects are predisposing to mastitis such as: pathogens can be easily transferred from one animal to another if care is not taken in the cleaning (washing and drying) of the ceilings and the hands of the milker or the milking machine; diffusion of the microorganisms between the mammary quarters, through reverse movements of the milk provided by the fluctuations in the vacuum system, besides being able to cause traumas in the teats and the process not to be fulfilled, leaving traces of milk in the teats and with it providing a means of growth bacterial; the roof channel itself if it is not well contracted may lead to the exposure of pathogens (Radostitis et al., 2007; Seyouma et al., 2018)

The antimicrobial susceptibility tests carried out in current analysis revealed low susceptibility of $S$. aureus to the usual antimicrobial agents. The average susceptibility $(67.7 \%)$ of $S$. aureus to all antimicrobial agents tested in this study corroborated data by Mesele et al., (2010) and Seyouma et al., (2018), but disagreed with other reports (Mekonnen et al., 2005; Amanu et al., 2016). According to Seyouma et al., (2018), divergence among different reports may be explained by difference in resistance level, pathogen strain, antimicrobial used and concentration, plus other related factors that affect the inhibition zone during antimicrobial susceptibility test.

Current study demonstrated zero susceptibility of $S$. aureus to penicillin $\mathrm{G}$, as Seyouma et al., (2018) reported in their study. This fact corroborates findings which reported $0 \%$ susceptibility of $S$. aureus to penicillin in Africa (Amanu et al., 2016 and Asmelash et al., 2016), but disagrees with results by Abera et al., (2013). Further, current study has also indicated low susceptibility of $S$. aureus to tetracycline, confirmed by different reports (Abebe et al., 2013; Asmelash et al., 2016; Seyouma et al., 2018). Mean susceptibility of 
$S$. aureus to the other antibiotics in current study reached $92 \%$, corroborating other studies (Amanu et al., 2016; Seyouma et al., 2018).

As a rule, current study demonstrated that susceptibility of $S$. aureus to the usual antimicrobials, such as penicillin $G$ and tetracycline, was very low. A possible justification for this fact would be the development of alarming resistance levels of $S$. aureus due to the regular use of common antibiotics for the treatment of cows. This fact may result in the spread of resistant strains in the area under analysis. Results corroborated reports from earlier studies in other countries (Edward et al., 2002; Jaims et al., 2008; Seyouma et al., 2018) and suggested a possible development of resistance to the prolonged and indiscriminate usage of some antimicrobial agents.

In this case, penicillin $\mathrm{G}$ is a great concern since it represents the main antibiotic groups recommended against Staphylococcal mastitis infection. Antibiotic resistance is carried on plasmids and transposons that can pass from one Staphylococcal species to another (Hulya et al., 2006; Seyouma et al., 2018). The resistance of $S$. aureus to penicillin may be attributed to the production of beta lactamase enzyme that hydrolyzes the beta-lactam ring of penicillin and inactivates it and other closely related antibiotics. It is believed that around $50 \%$ of mastitis causing $S$. aureus strains produces betalactamase (Green and Bradely, 2004; Seyouma et al., 2018). The low susceptibility of $S$. aureus isolates to this drug is evident.

Besides being a highly relevant human symptom, $S$. aureus is one of the major pathological agents of food poisoning. Its presence in milk and derivatives, such as cheese, the sample unit of current study, elucidated the use of raw material of infected animals (mastitis) or the possibility of contamination by handling agents. Farm dairies are located in close proximity to farms and the habitat of wild animals. Sampling the production stages from raw milk to cheese contributes towards our understanding of how $S$. aureus contamination pathways occur, and thus enable targeting control measures throughout the cheese-manufacturing process. In addition, based on what has been reported, these findings are extremely worrisome, especially because rates are very close to those required $\left(10^{5} \mathrm{CFU} \mathrm{g} \mathrm{mL}^{-1}-10^{9} \mathrm{CFU} \mathrm{g} \mathrm{mL}^{-1}\right)$ for enterotoxigenic strains for the production of enterotoxins in sufficient quantities for the occurrence of outbreaks of staphylococcal food poisoning.

The overall prevalence of Staphylococcus aureus in the population in the area under analysis was $48 \%$, respectively $50 \%$ and $40 \%$ in sub-clinical and clinical cases. Susceptibility of randomly selected isolates were also tested for the usual antimicrobial agents.

However, isolates have very low susceptibility, or rather, $0 \%$ to penicillin $\mathrm{G} ; 15 \%$ to tetracycline; good susceptibility for other antibiotics. Kanamycin proved to be the most effective drug. In addition to the susceptibility test, results revealed that $S$. aureus was the major problem, causing economic loss in dairy production, with public health hazard in area studied. There should be a regular antimicrobial sensitivity testing, not only in study area but, also at a national level, to select effective antibiotics against $S$. aureus mastitis. Dry cow therapy should be implemented for cows in the dry period. It is actually the most effective method of eliminating existing infections and preventing new infections during the period. Veterinarians should reduce uncontrolled and repeated use of drugs to minimize the development of drug resistance and food safety threat. Kanamycin should be encouraged to treat mastitis caused by $S$. aureus-infected cows in the area analyzed.

\section{References}

Abebe M, Daniel A, Yimtubezinash W, Genene T. 2013. Identification and antimicrobial susceptibility of Staphylococcus aureus 
isolated from milk samples of dairy cows and nasal swabs of farm workers in selected dairy farms around Addis Ababa, Ethiopia. African Journal of Microbiology Research 27, 3501-3510.

Abera M, Demie B, Aragaw K, Regassa F, Regassa A. 2013. Isolation and identification of Staphylococcus aureus from bovine mastitic milk and their drug resistance patterns in Adama town, Ethiopia. Journal of Veterinary Medicine and Animal Health 3, 29-34.

Amanu M, Gebremeskel M, Tadesse B. 2016. Prevalence and antibiotic resistance of Staphylococcus aureus mastitis in holeta area, western Ethiopia. Global Veterinary 4, 365-370.

Aqib AI, Ijaz M Anjum AA Malik MAR, Mehmood K Farooqi $\mathrm{SH}^{1}$ Hussain K. 2017. Antibiotic susceptibilities and prevalence of Methicillin resistant Staphylococcus aureus (MRSA) isolated from bovine milk in Pakistan. Acta Tropica 176, 168-172.

Asmelash T, Mesfin N, Addisu D, Aklilu F, Biruk T, Tesfaye S. 2016. Isolation, identification and drug resistance patterns of methicillin resistant Staphylococcus aureus from mastitic cow's milk from selected dairy farms in and around Kombolcha, Ethiopia. Journal of Veterinary Medicine and Animal Health $1,1-10$.

Barros LSS, Oliveira LP, Silva VC, Cirqueira MG. 2011a. Microbiological Quality and Detection of Antibiotic Residue in Raw and Pasteurized Milk Consumed in the Recôncavo Area of the State of Bahia, Brazil. Journal of Food Process and Technology 3, 10.4172/2157-71.

Barros LSS, Oliveira LP, Silva VC, Cirqueira MG. 2011b. Study of Staphylococcus aureus in raw and pasteurized milk consumed in the Recôncavo area of the State of Bahia, Brazil. Journal of Food Process and Technology 2, 1000128.

D'Amico DJ, Donnelly CW. 2011. Characterization of Staphylococcus aureus strains isolated from raw milk utilized in small-scale artisan cheese production. Journal of Food Protection 74, 1353-1358.

Duquenne M. Derzelle S, Fleurot I, Aigle M, Darrigo C, Hennekinne J-A, Mutel I, Bouix M, Deperrois-Lafarge V, Delacroix-Buchet, V. 2016. Milk maturation temperature and time are key technological parameters to limit staphylococcal enterotoxin production during uncooked semi-hard cheese manufacture. Food Control 59, 118-127.

Even S, Leroy S, Charlier C, Zakour NB, Chacornac JP, Lebert I, Jamet E, Desmonts $\mathrm{MH}$, Coton E, Pochet S, Donnio PY, Gautier M, Talon R, Le Loir Y. 2010. Low occurrence of risk factors in coagulase negative staphylococci isolated from fermented foodstuffs. International Journal of Food Microbiology 139 (1-2), 87-95.

Hennekinne J A, Yves Le Loir. 2014. Detection by Cultural and Modern Techniques. Encyclopedia of Food Microbiology, Academic Press - Elsevier, pp.3248, 2014, DOI 10.1016/B978-0-12-3847300.00318-9.

Jakobsen RA, Heggeb $\varnothing$ R, Sunde EB, Skjervheim M. 2011. Staphylococcus aureus and Listeria monocytogenes in Norwegian raw milk cheese production. Food Microbiology 28, 492-496.

Le Marc Y, Valík L, Medvedová, A. 2009. Modelling the effect of the starter culture on the growth of Staphylococcus aureus in milk. International Journal of Food Microbiology 129, 306-311.

Mehli L, Hoel S, Thomassen GMB, Jakobsen AN, Karlsen H. 2017. The prevalence, genetic diversity and antibiotic resistance of Staphylococcus aureus in milk, whey, and cheese from artisan farm dairies. International Dairy Journal 65, 20-27.

Mekonnen H., Workineh S, Bayleyegne M, Moges A, Tadele K. 2005. Antimicrobial susceptibility profile of mastitis isolates from the cows in three major Ethiopian dairies. Veterinary Medicine 7, 391-394. 
Mesele A, Demie B, Aragaw K, Regassa F, Regassa A, 2010. Isolation and identification of: $S$. aureus from bovine mastitic milk and their drug resistance patterns in Adama town. Journal of Veterinary Medicine Animal Health 3, 29-34.

Michelle A, 2011. Staphylococcus aureus Mastitis UK Veterinary Diagnostic Laboratory, and Jeffrey Bewley, Animal and Food Sciences. University of Kentucky College of Agriculture, Lexington, KY 40546.

NMKL. (009. Method no 66, 5th ed., Coagulase positive staphylococci. Enumeration in foods. Søborg, Denmark: Nordic Committee on Food Analyses. www.nmkl. org.

Peles F, Wagner M, Varga L, Hein I, Rieck P, Gutser K, Keresztúri P, Kardos G, Turcsányi I, Béri B, Szabó A. 2007. Characterization of Staphylococcus aureus strains isolated from bovine milk in Hungary. International Journal of Food Microbiology 118, 186-193.

Radostitis O, Gay D, Blood C, Hinchlif K, 2007. Mastitis. Veterinary Medicine, $9^{\text {th }}$ ed. Harcourt Ltd, London, pp. 174-758.

Rahman HD, Fowbyal S, Boxi KK. 2009. Incidence and etiology of sub-clinical mastitis in cows and buffalos in Punjab. Journal Research Punga Agriculture Universal 20, 208-211.

Rajic-Savic N, Katic V, Velebit B, Colovic S. 2015. Characteristics of enterotoxigenic coagulase positive staphylococci isolated from bovine milk in cases of subclinical mastitis. Procedia Food Science 5, 250 253.
Rosengren A. Fabricius A, Guss B, Sylvén S, Lindqvist, R. 2010. Occurrence of foodborne pathogens and characterization of Staphylococcus aureus in cheese produced on farm-dairies. International Journal of Food Microbiology 144, 263269.

Sandes AB, Barros LSS, Silva MH, Santos, ESV. 2016. Count of microorganisms in milk obtained by milking mechanized and mechanized not of Recôncavo baiano. Revista Brasileira de Higiene e Sanidade Animal 10, 396-414.

Santos ML, Barros LSS, Silva IM, Andrade MVS, Lima, DV. 2016. Escherichia coli O157, Staphylococcus aureus and coliforms in crude and processed bovine milk marketed. African Journal of Microbiology Research 10, 1888-1893.

Seyouma B, Kefyalewa H, Aberab B, Abdelac N. 2018. Prevalence, risk factors and antimicrobial susceptibility test of Staphylococcus aureus in Bovine cross breed mastitic milk in and around Asella town, Oromia regional state, southern Ethiopia. Acta Tropica 177, 32-36.

Tessema F. 2016. Prevalence and drug resistance patterns of Staphylococcus aureus in lactating dairy cow's milk in Wolaita Sodo, Ethiopia. EC Veterinary Science 2, 226-230.

Walcher G, Gonano M, Kümmel J, Barker GC, Lebl K, Bereuter O, Ehling-Schulz M, Wagner M, Stessl B. 2014. Staphylococcus aureus reservoirs during traditional Austrian raw milk cheese production. Journal of Dairy Research 81, 462-470.

\section{How to cite this article:}

Ludmilla Santana Soares e Barros, Jana Kelly dos Santos and Adriana dos Santos Silva. 2018. Prevalence of Staphylococcus aureus and Antimicrobial Susceptibility Test in Milk and Cheese from Hadman Farm Dairies. Int.J.Curr.Microbiol.App.Sci. 7(06): 765-774. doi: https://doi.org/10.20546/ijcmas.2018.706.089 